Pensamiento Crítico Vol.17 № 2, pp. 137-153

\title{
Algunos efectos de la expansión monetaria en las tasas de interés del mercado de préstamos
}

\author{
Pablo Rivas Santos ${ }^{1}$
}

\section{RESUMEN}

Este artículo señala que el empresario que prevé un alza de precios busca préstamos en el mercado dispuesto a pagar mayores intereses. El prestamista que prevé un alza de precios, solo otorga préstamos si el interés de mercado sube por encima del interés del mercado que prevalecía en una situación en la que se preveía una menor alza de precios. Al empresario no le asusta ese mayor interés de mercado; si considera que su proyecto será de tal rentabilidad que podrá soportar ese mayor interés de mercado. Tal prevista alza de precios desata una tendencia alcista del interés de mercado. Al variar la relación monetaria de origen monetario como ocurrió entre 1963-1993 previéndose una alza de precios; predominó la tendencia alcista del interés de mercado. Entonces, en todo préstamo se incorpora una Compensación por Alza de Precios.

En el análisis del proceso de expansión monetaria, suponemos que la presencia de dinero adicional en el mercado de préstamos perturba la adecuación del sistema económico a la circunstancia del mercado de préstamos; perturbando la tendencia hacia determinados precios y tasas de interés.

La variación de la relación monetaria de origen monetario no afecta al mismo momento, ni en la misma proporción, a precios, salarios e intereses. Tal variación

1 Profesor de Economía e investigador del Instituto de Investigaciones Económicas de la Facultad de Ciencias Económicas de la Universidad Nacional Mayor de San Marcos. 


\section{Pensamiento Crítico Vol. 17 No 2}

afecta al interés porque esa diferente reacción de precios; modifica la renta y riqueza de la gente. La modificación temporal del interés es una prueba más de esa diferente reacción de precios. Cuanto más temprano acuda al mercado de préstamo el nuevo dinero, con mayor violencia será afectada el interés.

Palabras clave: Relación monetaria; interés; cálculo empresarial; Componente por alza de precios.

\section{ABSTRACT}

This article states that an employer who provides a price increase in the market looking for loans willing to pay higher interest. The lender that provides a price increase, only provides loans if the market interest rises above the prevailing market interest in a situation where an expected retail price increases. The entrepreneur is not afraid that higher market interest, if you think your project will cost so that you can withstand that higher market interest. Such price increases planned unleashes an upward trend in market interest. By varying the ratio of monetary currency as occurred between 1963-1993 foreseeing a rise in prices, the upward trend prevailing market interest. So every loan is incorporated in a Compensation for rising prices.

In the analysis of monetary expansion process, we assume that the presence of extra money in the loan market disturbs the adequacy of the economic system to the circumstances of the loan market, disturbing trend towards certain prices and interest rates.

The variation of the ratio of monetary currency at the same time does not affect, nor in the same proportion, prices, wages and interest. Such variation affects the interest because that different reaction rates, changes in income and wealth people. The temporary modification of interest is further evidence that different reaction rates. The earlier you go to market the new money loan, more interest will be affected violence.

Keywords: Relationship monetary interest, business calculations; component price gouging. 


\section{Pablo Rivas Santos}

\section{Introducción}

El prestamista es un empresario, porque conceder un préstamo es un acto empresarial y especulativo, cuyo futuro resultado es incierto. El prestamista sabe que puede perder la totalidad o parte del principal. Tal riesgo condiciona un préstamo.

Prestamista y prestatario pueden caer en insolvencia porque las hipotecas y otras garantías aportadas pueden desvalorarse. El prestamista aparece como virtual copropietario de los bienes que asegura el préstamo. Cualquier cambio en el mercado que influya en el valor de esos bienes afecta al prestamista. El capital es necesario invertirlo acertadamente, para que produzca interés y el principal no se pierda. Solo percibe interés de mercado; el prestamista que acertadamente concede préstamos. Así, el interés de mercado incluye un componente empresarial.

El componente empresarial se distingue entre préstamos de consumo y préstamos empresariales. El préstamo de consumo permite al prestatario gastar por adelantado sus previstos ingresos futuros. El prestamista adquiere condición empresarial al adquirir derecho a una parte de esos previstos ingresos. Es incierto el buen fin de tal préstamo, porque no hay seguridad absoluta de la aparición de esos previstos ingresos.

El componente empresarial se distingue entre préstamos a privados y préstamos al gobierno. La incertidumbre de préstamos al gobierno está en el ignorado plazo de sobrevivencia de los poderes políticos. Los gobiernos son derribados electoralmente como el de 1980-1985; tal vez los gobiernos como el de 1985-1990 se nieguen pagar las deudas contraídas por sus antecesores.

El riesgo político (implícito en tal préstamo) influye en el componente empresarial del interés de mercado. En el periodo 1985-1990 (cuando se preveía la eliminación de los pagos aplazados) el componente empresarial se incrementó exageradamente.

En la economía, los precios fluctúan y los empresarios acomodan sus actuaciones a esas fluctuaciones. Porque los empresarios prevén fluctuaciones y de ellas pretenden obtener ganancias, ellos se lanzan a actuaciones de mercado. Los empresarios más emprendedores y prudentes buscan ganancia readaptando continuamente la producción, para atender necesidades que los consumidores ya sienten y conocen; y necesidades 


\section{Pensamiento Crítico Vol. $17 \mathrm{~N}^{\circ} 2$}

que todavía no sienten ni conocen. Dichas actuaciones especulativas revolucionan diariamente la estructura de precios, provocando variaciones del interés de mercado.

El empresario que prevé un alza de precios busca préstamos en el mercado; dispuesto a pagar mayores intereses. El prestamista que prevé un alza de precios, solo otorga préstamos si el interés de mercado sube por encima del interés del mercado que prevalecía en una situación en la que se preveía una menor alza de precios. Al empresario no le asusta ese mayor interés de mercado; si considera que su proyecto será de tal rentabilidad que podrá soportar ese mayor interés de mercado. Tal prevista alza de precios desata una tendencia alcista del interés de mercado. Al variar la relación monetaria de origen monetario como ocurrió entre 1963-1993 previéndose una alza de precios; prevalece la tendencia alcista del interés de mercado. Entonces, en todo préstamo se incorpora una compensación por alza de precios.

Tal compensación la genera la propia idea que la gente se forma del futuro; y los cálculos que la gente se formula partiendo de cierta base. Tal compensación va gradualmente tomando cuerpo, a medida que, primero, unas pocas personas $y$, después, un mayor número de personas; se dan cuenta que el mercado se halla bajo los efectos de una variación de la relación monetaria de origen monetario, variación que desata una tendencia alcista de precios. Solo cuando la gente comienza a comprar con el fin de ganar, se materializa tal compensación.

La compensación surge al amparo de consideraciones relacionadas a cambios previstos de la relación monetaria; la genera (en caso de suponerse el mantenimiento de tendencias inflacionistas) las primeras manifestaciones de ese fenómeno que luego, al generalizarse, se califica de huida hacia valores reales; y provocará el cataclismo económico y la desarticulación del sistema monetario.

Esa mayor propensión a comprar (que materializa la compensación por alza de precios) afecta (rápidamente y en mayor grado) al mercado de préstamos a corto plazo que al mercado de préstamos a largo plazo. Los préstamos a corto plazo registran primeramente esa compensación; y después esa compensación se traslada al mercado de préstamos a largo plazo. Sin embargo, puede suceder que esa compensación aparezca en los préstamos a largo plazo independientemente de lo que suceda con los préstamos a corto plazo. En el mercado internacional de préstamos, sucede ese fenómeno: los 


\section{Pablo Rivas Santos}

prestamistas que tienen confianza en el futuro cercano de la moneda nacional exigen una menor compensación por préstamos a corto plazo. Sin embargo, el futuro lejano, no es tan bueno; y por tanto, en los préstamos a largo plazo se incluye una mayor compensación. Consecuentemente, los préstamos a largo plazo en moneda nacional al gobierno, solo se colocan si sus condiciones son más favorables para el prestamista; que las condiciones para préstamos pagaderos en moneda extranjera.

Se ha visto el primer motivo por el que la compensación amortigua los efectos de las variaciones de la relación monetaria de origen monetario sobre los respectivos préstamos de los contratantes. La compensación se demora con respecto a las variaciones del poder de compra del dinero; porque la compensación es efecto provocado por los efectos (posteriores) que produce el aumento de la oferta de dinero en la estructura de precios. Es al final de prolongada inflación (como de 1963-1993) cuando las cosas cambian. Al aparecer el pánico de la desarticulación del sistema monetario (al producirse el cataclismo económico) habrá alza exagerada de precios y de la compensación. Ningún interés de mercado, por grande que sea, es suficiente al potencial prestamista cuando piensa en las pérdidas que le ocasionará la creciente baja del poder de compra del dinero. El potencial prestamista dejará de prestar, prefiriendo invertir su dinero en bienes "reales". El mercado de préstamos se paraliza (como en 1988-1990).

\section{Incidencia de la expansión monetaria en el mercado de préstamos}

El componente empresarial cambia según las circunstancias de cada préstamo. Son diferentes las circunstancias institucionales que regulan la actividad: del BCR y la banca privada de cada país ${ }^{2}$, y los respectivos mercados de préstamos; que confunde comparar las correspondientes tasas de interés sin ponderar debidamente las específicas diferencias de cada caso. En el mercado de préstamos prevalece la tendencia a igualar el interés de mercado de préstamos de una misma clase en lo relacionado al componente empresarial y a la compensación por variación de precios.

Hay diferencia entre el mercado de préstamos a corto plazo (mercado de dinero) y el mercado de préstamos a largo plazo (mercado de capitales). La diferencia más sobresaliente entre las tasas de interés resultan del componente empresarial.

2 Una misma tasa de interés referencial del BCR tiene diferente valor según el momento en que rija. 


\section{Pensamiento Crítico Vol. $17 \mathrm{~N}^{\circ} 2$}

El empresario que reajusta el uso de sus factores de producción a las cambiantes circunstancias; basa sus cálculos en precios e interés que determina el mercado.

El empresario se da cuenta de la diferencia entre precio corriente de factores de producción complementarios y precio previsto del producto final (una vez deducido del precio del producto final el interés de mercado) aspirando a beneficiarse con tal diferencia. Es la función que desempeña el interés en los cálculos del empresario.

El monto del interés indica al empresario: hasta qué punto puede desviar factores de producción que atienden necesidades temporalmente más cercanas para dedicarlos a atender necesidades temporalmente más lejanas; cuál será el periodo de producción que (en cada caso) se ajusta al diferente valor que la gente otorga a bienes presentes con respecto a bienes futuros; y a no lanzarse a empresas que no se compaginen con las limitadas existencias de capitales ahorrada por la gente.

Las variaciones de la relación monetaria (como ocurrió entre 1963-1993) afectó al mercado de préstamos antes que a los precios. El aumento de la oferta de dinero aumentó la oferta de dinero del mercado de préstamos, provocando alza del interés de mercado. En tal supuesto empírico, el interés de mercado se apartó del interés de los disponibles capitales. Entonces el interés de mercado deja de cumplir su función de guiar y orientar las decisiones empresariales, y trastorna los cálculos del empresario, apartando el interés de aquellas vías que mejor atenderían las más urgentes necesidades de los consumidores.

\section{Efectos de la variación de la relación monetaria de origen monetario}

Depende de particulares circunstancias de cada caso; que el alza de salarios nominales se retrase en relación al alza de precios. La baja del poder de compra del dinero no provoca por sí sola la baja de salarios reales. Puede darse el caso en que los salarios nominales se incremente más pronto y en mayor proporción que los precios.

Cabe que quienes vean incrementados sus ingresos, gracias a la inflación, no ahorren tales excedentes, dedicándolos al consumo. Es imposible predecir, con certeza, cómo actuarán aquellos a quienes la inflación privilegia. 


\section{Pablo Rivas Santos}

La inflación (como en 1980-1990) pone en marcha fuerzas que abogan por el consumo de capital. Uno de los efectos de la inflación es falsear el cálculo económico y la contabilidad de capitales; apareciendo ganancias ficticias.

Si las cuotas de amortización no se aplican tomando en cuenta que la reposición de piezas gastadas de la máquina exige un gasto superior a la suma que esas piezas costaron en su día, esas cuotas serán insuficientes.

Esa ganancia ficticia hace creer a muchos que la inflación trae prosperidad, lo que provoca alegría y desprendimiento en gastos. Al gastar esas ganancias ficticias (generadas por falseados cálculos) los empresarios consumen su capital. No tiene importancia quienes sean personalmente tales malgastadores. Da igual se trate de empresarios o trabajadores; tal vez sean trabajadores cuyas demandas por mayores sueldos fueran alegremente atendidas por empresarios que se consideraban cada día más ricos.

A medida que avanza la inflación, un número cada vez mayor de personas advierte la creciente desvalorización del dinero. La gente no conocedora de asuntos bursátiles ahorra en bancos, compra bonos públicos o paga seguros de vida. La inflación desvaloriza todo ese ahorro. Los ahorristas se desaniman; el consumo de capital se impone. La posterior reacción del público, la huida hacia valores reales, constituye desesperado intento por salvar algo de la ruina ya irremediable. Se trata de proteger, mediante fórmulas de emergencia, alguna fracción del capital.

\section{Efectos de la expansión monetaria y la inflación en las tasas de interés}

Suponemos que la expansión monetaria aparece en el mercado de préstamos a través de nuevos préstamos.

Al comenzar la expansión monetaria; la compensación por alza de precios toma cuerpo a medida que el dinero adicional comienza a subir los precios. Mientras se mantiene esa expansión monetaria, inyectándose continuamente nuevo dinero al mercado de préstamos; el interés se mantiene reprimido: el interés debería subir por esa compensación por alza de precios (compensación que sube continuamente a medida que avanza el proceso expansionista). Pero, el interés queda rezagado sin alcanzar el monto necesario para abarcar esa compensación por alza de precios. 


\section{Pensamiento Crítico Vol. $17 \mathrm{~N}^{\circ} 2$}

Al subir los precios, el interés sube con esa compensación por alza de precios. Este fenómeno se produce en toda prolongada expansión monetaria. El interés sube durante el curso de toda expansión monetaria; pero resulta menor en comparación con la previsible alza posterior de precios.

En el análisis del proceso de expansión monetaria, suponemos que la presencia de ese dinero adicional en el mercado de préstamos perturba la adecuación del sistema económico a la circunstancia del mercado de préstamos; perturbando la tendencia hacia determinados precios y tasas de interés ${ }^{3}$.

Una baja artificial del interés falsea el cálculo empresarial porque (pese a que no hay una mayor cantidad de bienes de capital disponible) se incluyen en tal cálculo parámetros que solo proceden si hay una mayor cantidad de bienes de capital disponible. Tal cálculo hace parecer rentables negocios que no lo serían; si el interés no hubiera bajado artificialmente mediante esa expansión monetaria. Los empresarios, motivados, se lanzan a tales negocios. Comienza el periodo de auge.

La mayor demanda de los empresarios (que amplían sus operaciones) pone en marcha una tendencia al alza de precios de los factores de producción. Al subir estos precios; los precios de los bienes de consumo también suben. Los empresarios contribuyen a esa subida de precios de bienes de consumo; pues, engañados por unas ilusorias ganancias que arrojan sus libros contables, incrementan su consumo personal. La subida de precios de los bienes de consumo crea optimismo. La mayor demanda de bienes de consumo y el aumento de las ventas (pese a la subida de precios de factores de producción) tranquiliza sus inquietudes, no obstante esa subida de precios de factores de producción; los empresarios confían en que las operaciones resultarán beneficiosas y prosiguen las operaciones sin mayor preocupación.

3 Antes que aparezca ese dinero adicional; toda persona que estaba dispuesto a pagar el interés prevaleciente; podía obtener préstamos. Mayor cantidad de préstamos solo cabía colocarla bajando el interés. Así, una baja del interés influye en los cálculos de la rentabilidad de las proyectadas operaciones del empresario; porque el empresario pondera, en tales cálculos, el precio de factores de producción; el precio de venta previsto para su producción; y el interés. El resultado de tales cálculos le indica si el negocio es o no rentable; le informa qué inversiones cabe efectuar dada la razón entre el valor que el público otorga a los bienes presentes y bienes futuros; le obliga a acomodar sus actuaciones a tal valoración; le impide realizar proyectos que repugnan a los consumidores; y le obliga a emplear los bienes de capital que de la mejor manera satisfagan las necesidades más deseadas de la gente. 


\section{Pablo Rivas Santos}

Para financiar la producción (que provoca esa expansión monetaria ) en esa mayor escala; los empresarios (los que ampliaron sus negocios y los que mantienen fijos sus negocios) necesitan mayores fondos de maniobra, al subir los precios de los factores de producción. Si esa expansión monetaria consiste en una única inyección de dinero en el mercado de préstamos, ese período de auge tendrá corta vida. Los empresarios no obtendrán los fondos que exige la continuidad de sus operaciones. Sube el interés; porque el efecto de la nueva demanda de préstamos no es anulado por el aumento de dinero disponible para prestar. Los precios de bienes de consumo bajan en razón a que algunos empresarios venden inventarios, mientras que otros empresarios restringen sus compras. La actividad en el mercado vuelve a contraerse. Finaliza ese periodo de auge porque las fuerzas que lo crearon han dejado de actuar. Aquel crédito adicional ha agotado su capacidad de influir sobre precios y salarios. Precios, salarios y saldos dinerarios de la gente se acomodan a la nueva relación monetaria; todos ellos se mueven hacia la nueva situación final correspondiente a esa nueva relación monetaria, sin que tal tendencia se vea perturbada por nuevas inyecciones adicionales de dinero.

Así, para explicar ese periodo de auge (la tendencia general a ampliar las actividades en el mercado y la subida de precios) se debe mencionar la expansión monetaria. Para que se produzca un alza de precios es necesario que aumenten las existencias de dinero.

Toda expansión monetaria provoca auge. Tal potencia de la expansión monetaria se debilita si al mismo tiempo aparecen otras circunstancias de signo opuesto: si (pese a que los bancos intentan ampliar los préstamos) la gente está convencida de que el gobierno confiscará con impuestos las extraordinarias ganancias del caso (o la gente está convencida de que esa actividad bancaria será cortada tan pronto como comiencen a subir los precios) es imposible que se produzca ese auge. En tal supuesto, los empresarios no ampliarán sus negocios ni harán uso del crédito barato ofrecido por la banca, porque, ninguna ganancia personal podía reportarles tales actuaciones.

El auge persiste si se mantiene a ritmo más acelerado la expansión monetaria. $\mathrm{El}$ auge se cae tan pronto dejan de inyectarse nuevo dinero al mercado de préstamos. Aunque se mantuvieran la expansión monetaria, tal circunstancia no permitiría la sobrevivencia indefinida del auge. Entonces aquellos factores que impiden proseguir ininterrumpidamente la expansión monetaria entrarían en juego. Se produciría la quiebra económica, la ruina del sistema monetario. 


\section{Pensamiento Crítico Vol. $17 \mathrm{~N}^{\circ} 2$}

La variación de la relación monetaria de origen monetario no afecta ni al mismo momento ni en la misma proporción, a precios, salarios e intereses. Esa variación afecta al interés porque esa diferente reacción de precios modifica la renta y riqueza de la gente. Esa modificación temporal del interés es una prueba más de esa diferente reacción de precios. Cuanto más temprano acuda al mercado de préstamo el nuevo dinero, con mayor violencia será afectada el interés.

Cuando (bajo una expansión monetaria) el dinero adicional es invertido en préstamos al empresariado; la actividad del mercado aumenta. Los empresarios amplían horizontalmente la producción (alargan el período de producción). Esa ampliación horizontal de la producción exige inversión de adicionales factores de producción iPero, la cantidad de bienes de capital no ha aumentado! Por otra parte, esa expansión monetaria no aboga por la restricción del consumo. Al considerar el ahorro forzoso, es cierto que después (según vaya progresando la expansión monetaria) una parte de la población restringirá su consumo. No obstante, depende de las circunstancias de cada caso que el ahorro forzoso de unos grupos supere el mayor consumo de otros grupos, provocando un incremento del ahorro. El efecto inmediato de la expansión monetaria es el aumento del consumo de aquellos trabajadores cuyos ingresos han aumentado a causa de la mayor demanda de trabajadores desatada por empresarios cuyas actividades se amplían. Supongamos que ese mayor consumo de los grupos favorecidos por la expansión monetaria se compensa con la reducción de consumo que se ha impuesto en los otros grupos perjudicados por la inflación; de tal suerte que, en conjunto, el consumo permanece inalterado. La situación es que se ha ampliado la producción en el sentido de alargar el período de espera. Pero, la demanda de bienes de consumo no se ha restringido. Tal situación sube los precios de bienes de consumo, lo cual pone en marcha la tendencia al ahorro forzoso. Esa subida de precios de bienes de consumo refuerza la tendencia expansiva de la industria. De la subida de la demanda y precios, los empresarios deducen que es rentable invertir y producir más. Los empresarios insisten y su intensiva actividad da lugar a una nueva subida de precios de factores de producción y, consecuentemente, una subida de precios de bienes de consumo. Los negocios continuarán ampliándose mientras los bancos sigan dispuestos a prestar más.

Al comenzar la expansión monetaria, se materializaban todos aquellos proyectos que eran rentables, dadas las específicas circunstancias del mercado. El sistema se movía hacia una situación en la que encontrarían trabajo cuantos quisieran trabajar por cuenta 


\section{Pablo Rivas Santos}

ajena, aprovechándose los factores de producción inconvertibles en el grado aconsejado: por la demanda de los consumidores y por las disponibles existencias de trabajo y de factores de producción no específicos. La correspondiente producción solo podía ser ampliada si un nuevo ahorro incrementaba los bienes de capital. Sin embargo, esos adicionales bienes de capital no han sido producidos cuando la expansión monetaria provocó el auge. En consecuencia, esos adicionales bienes de capital necesarios para ampliar la producción serán sustraídos de otras producciones.

Sea $\mathrm{K}$ bienes de capital al comenzar la expansión monetaria y $\mathrm{C}$ bienes de consumo producidos por esos $\mathrm{K}$ bienes de capital. Los empresarios motivados por esa expansión monetaria, producen un adicional $\mathrm{C}_{3}$ bienes de consumo que antes se producía y un $\mathrm{C}_{4}$ bienes de consumo que antes no se producía. Para producir $\mathrm{C}_{3}$ se necesita un adicional bien de capital $\mathrm{K}_{3}$ y para producir $\mathrm{C}_{4}$ se necesita un adicional bien de capital $\mathrm{K}_{4}$. Pero, como ese $\mathrm{K}$ permanece constante ni $\mathrm{K}_{3}$ ni $\mathrm{K}_{4}$ existen. En esto se diferencia un auge artificial creado en base a expansión monetaria; de un auge creado con participación de $\mathrm{K}_{3}$ y $\mathrm{K}_{4}$.

Sea $\mathrm{X}$ bienes de capital que (extraído de la producción de determinado periodo) se destina a reponer el desgaste de ese $\mathrm{K}$ durante el proceso productivo. Si X se destina a reponer, cabe producir nuevamente esos $\mathrm{C}$ en el siguiente periodo; pero si $\mathrm{X}$ no se destina a reponer el desgaste de $\mathrm{K}$, ese $\mathrm{K}$ disminuye en $\mathrm{X}$ y entonces $\mathrm{K}-\mathrm{X}$ solo producirá C-A en el siguiente periodo.

Suponemos que la economía es afectada por esa expansión monetaria. Esa economía (en el período anterior a esa expansión monetaria) producía adicionales bienes de capital $\mathrm{K}_{1}+\mathrm{K}_{2}$ : en ausencia de esa expansión monetaria $\mathrm{K}_{1}$ se hubiera dedicado a producir un adicional $\mathrm{C}_{1}$ bienes de consumo que antes se producía; y $\mathrm{K}_{2}$ se hubiera dedicado a producir bienes de consumo $\mathrm{C}_{2}$ que antes no se producía.

Los bienes de capital que disponen los empresarios son $\mathrm{X}+\mathrm{K}_{1}+\mathrm{K}_{2}$. Sin embargo, los empresarios confundidos por esa expansión monetaria, actúan como si tuvieran $\mathrm{X}+\mathrm{K}_{1}+\mathrm{K}_{2}+\mathrm{K}_{3}+\mathrm{K}_{4}$ bienes de capital y consecuentemente como si estuviera en sus manos producir $\mathrm{C}+\mathrm{C}_{1}+\mathrm{C}_{2}+\mathrm{C}_{3}+\mathrm{C}_{4}$. Los empresarios pujan por unos bienes de capital insuficientes para llevar adelante sus planes excesivamente ambiciosos. 


\section{Pensamiento Crítico Vol. $17 \mathrm{~N}^{\circ} 2$}

Al comenzar la expansión monetaria, el alza de precios de factores de producción sobrepasa al alza de precios de bienes de consumo. En tal caso, se observa una tendencia a la baja del interés. Pero, al seguir la expansión monetaria, esa alza de precio de bienes de consumo sobrepasará el alza de precio de factores de producción. El alza de salarios y de ganancias (de prestamistas y empresarios), si bien en gran parte son nominales, intensifican la demanda de bienes de consumo. La intensa demanda de bienes de consumo afecta al mercado mucho antes de que las nuevas inversiones hayan podido crear más y nuevos bienes de consumo. El interés vuelve a subir. La tendencia al alza del interés sustituye a la tendencia a la baja del interés que se produce al comenzar la expansión monetaria.

Esta tendencia al alza del interés y la aparición de la compensación por alza de precios permite comprender determinadas circunstancias que acompaña al auge. Los bancos se encuentran con una mayor demanda de préstamos. Los empresarios están dispuestos a pagar mayores intereses. Estos siguen concertando préstamos pese a que los bancos cobran más caro el préstamo. El interés es superior al interés que regía antes de la expansión monetaria. Sin embargo, el alza del interés se ha retrasado, siendo su nivel insuficiente para cubrir el componente empresarial y la compensación por alza de precios. Los banqueros al inyectar en el mercado de préstamos más dinero adicional, promueven el auge. Es la continua creación de dinero lo que produce, alimenta y acelera el auge. El alza del interés es consecuencia de ese dinero adicional. Para averiguar si una economía sufre o no una expansión monetaria hay que examinar el dinero adicional.

Solo cabe aumentar las inversiones si se dispone de nuevos bienes de capital. $\mathrm{El}$ auge aumenta el consumo. $\mathrm{El}$ auge supone inversiones torpes e inoportunas. Los empresarios pretenden emplear $\mathrm{X}+\mathrm{K}_{1}+\mathrm{K}_{2}$ como si tratara de $\mathrm{X}+\mathrm{K}_{1}+\mathrm{K}_{2}+\mathrm{K}_{3}+\mathrm{K}_{4}$. Los empresarios amplían la producción para alimentar inversiones; para las que son insuficientes los bienes de capital disponibles. Tales proyectos no pueden tener buen fin, pues, no bastan los bienes de capital existentes. Tarde o temprano, tan desmesuradas operaciones se caen. El mal final de toda expansión crediticia de pronto aclara los errores antes cometidos. Hay industrias que no pueden funcionar por faltarles factores de producción complementarios que todavía no se producen; hay bienes de consumo que no es posible vender porque los consumidores prefieren otros bienes que no se fabrican en cantidad suficiente; $y$ hay instalaciones a medio construir que no se concluyen porque su explotación produce pérdidas. 


\section{Pablo Rivas Santos}

Las malas inversiones no proceden porque se carece de industrias necesarias para fabricar los necesarios factores de producción complementarios; y los bienes de consumo que el público necesita más urgentemente. Toda ampliación de la producción se comienza incrementando factores de producción empleados en las etapas más alejadas de los bienes de consumo: para ampliar la producción de zapatos, telas, muebles $\mathrm{y}$ viviendas es necesario comenzar ampliando la fabricación de acero, cobre y otros factores de producción. Si se quiere invertir $\mathrm{X}+\mathrm{K}_{1}+\mathrm{K}_{2}$ (que producen $\mathrm{A}+\mathrm{C}_{1}+\mathrm{C}_{2}$ ) como si fuera $\mathrm{X}+\mathrm{K}_{1}+\mathrm{K}_{2}+\mathrm{K}_{3}+\mathrm{K}_{4}$ (que producen $\mathrm{X}+\mathrm{C}_{1}+\mathrm{C}_{2}+\mathrm{C}_{3}+\mathrm{C}_{4}$ ) es necesario ampliar la producción de bienes e instalaciones cuya participación será previamente requerido; si ha de llevarse a cabo ese ampliado proceso productivo. Los empresarios se asemejan a un constructor que pretende construir una casa; con una limitada cantidad de materiales de construcción. Si sobreestima sus disponibilidades, trazará proyectos que exceden la capacidad de los medios: dedicará una parte excesiva de los medios a trabajos de excavación y cimentación, para después darse cuenta que con los materiales restantes no puede terminar la casa. El error del constructor consistió en efectuar inversiones equivocadamente, sabiendo de los medios que disponía.

El empresario, al enfrentarse con la restricción de préstamos (con ocasión de la crisis), lamentará haber invertido demasiados fondos en la ampliación de sus instalaciones y adquisición de maquinarias; hoy su posición sería más holgada si pudiera disponer de esos fondos para la normal gestión del negocio. Cuando el auge se transforma en depresión, caracteriza a tal depresión el que la oferta de materias primas y bienes alimenticios es tan abundante que echa por tierra sus precios.

La ampliación de los recursos productivos y la capacidad de las industrias; el reforzar la fabricación de bienes duraderos, es típico de todo periodo de auge crediticio. Los economistas están en lo cierto al ver la señal del ciclo económico en las cifras de la producción de esas industrias.

El auge también influye en las industrias de bienes de consumo. Las nuevas empresas y la ampliación de las empresas ya existentes no ofrecen a los consumidores aquellos bienes de consumo que estos desean con mayor intensidad. Los empresarios han trazado planes pretendiendo producir $\mathrm{X}+\mathrm{C}_{1}+\mathrm{C}_{2}+\mathrm{C}_{3}+\mathrm{C}_{4}$. El exagerado carácter de tal pretensión lo hace inviable. Una marcada subida de precios no es fenómeno que necesariamente acompaña al auge: el aumento de dinero adicional tiende teóricamente 


\section{Pensamiento Crítico Vol. $17 \mathrm{~N}^{\circ} \mathrm{Z}$}

a subir los precios. Sin embargo, cabe que tal tendencia tropiece con fuerzas de signo contrario que reduzcan el alza de precios o la supriman por completo. El periodo 20002012, durante el cual el suave y ordenado funcionamiento del mercado se vio una y otra vez golpeado por actividades expansionistas, fue un período de continuo progreso económico. La incesante acumulación de nuevos capitales permitió implantar los últimos progresos de la técnica. Se incrementó la productividad por unidad de inversión; y la actividad comercial abasteció los mercados con cantidades crecientes de bienes baratos. $\mathrm{Si}$, en ese período, el aumento de dinero no hubiera sido tan marcado como lo fue, se habría registrado una tendencia a la baja de los precios. Las expansiones monetarias de 2006-2012, se han producido sobre un trasfondo de poderosas fuerzas que se oponían al alza de precios. Sin embargo, en tal pugna prevalecieron las tendencias encarecedoras. Sin embargo, también hubo casos en que la subida de los precios fue muy reducida; un ejemplo es la expansión monetaria de 2000-2006.

Lo que lanza al empresario a producir son la discrepancia entre los costos de producción (que incluye el interés) y el precio previsto de los productos finales. La baja del interés que provoca la expansión monetaria hace que parezcan rentables proyectos que antes no lo eran; da lugar a que $\mathrm{X}+\mathrm{K}_{1}+\mathrm{K}_{2}$ se manejen como $\mathrm{X}+\mathrm{K}_{1}+\mathrm{K}_{2}+\mathrm{K}_{3}+\mathrm{K}_{4} \mathrm{y}$ estructura la producción e inversión en desacuerdo con las existencias de bienes de capital.

En ningún caso, la manipulación bancaria genera los bienes que necesita el mercado. Para una efectiva expansión de la producción, lo que se necesita son nuevos bienes de capital; no dinero adicional.

La crisis aparece cuando los bancos se inquietan ante el acelerado paso de la inflación y pretenden reducir la expansión monetaria. El auge se mantiene mientras sigan concediéndose préstamos a las empresas para continuar sus exagerados planes disconformes con las existencias de factores de producción y las auténticas valoraciones de los consumidores. Sin embargo, aquellos planes ficticios que parecen practicables a causa del falseamiento del cálculo económico (provocado por la política de dinero barato) solo pueden ser financiados mediante préstamos otorgados con un interés artificialmente rebajado en relación con el interés que regiría en un mercado de préstamos inadulterado. Ese margen hace rentable, en apariencia, esos planes. El cambio de actitud de los bancos pone de manifiesto el daño provocado por los errores que se cometieron durante el periodo de auge. 


\section{Pablo Rivas Santos}

Aunque los bancos persistieran tercamente en su actitud expansionista, no por ello el auge podría mantenerse eternamente. Fracasa todo intento de reemplazar unos inexistentes bienes de capital $\mathrm{K}_{3}$ y $\mathrm{K}_{4}$ por dinero adicional. Si la expansión monetaria no se detiene a tiempo, el auge da paso a la catástrofe monetaria; aparece la huida hacia valores reales y todo el sistema monetario se cae.

Tan pronto se detiene la creación de dinero adicional, el auge se cae. Los empresarios se ven obligados a restringir sus actividades, al carecer de fondos exigidos para continuar las actividades ante la exagerada escala comenzada. De pronto, caen los precios, porque hay empresas que están deshaciéndose de sus inventarios a cualquier precio. Las fábricas cierran; iniciados proyectos se interrumpen; comienza el despido de obreros. Comoquiera que, por un lado, hay empresas que desesperadamente necesitan dinero para evitar la quiebra y, por otro lado, ya nadie goza del préstamo antes tan generosamente concedido a todos, el componente empresarial del interés sube exageradamente.

Circunstancias accidentales de carácter institucional y psicológico transforman el comienzo de la crisis en pánico abierto. El auge (creado por la expansión monetaria) da paso a la depresión; en la depresión toma cuerpo el proceso de reacomodar la producción: a las circunstancias del mercado, a las disponibles existencias de factores de producción a las preferencias de los consumidores, $y$, al interés según se refleja en las valoraciones del público.

Esas circunstancias ya no son iguales a las circunstancias que prevalecían al comenzar la expansión monetaria. El ahorro forzoso y el ahorro para el consumo futuro posiblemente hayan producido nuevos bienes de capital; que es de esperar no se habrán esfumado a causa del sobreconsumo y malas inversiones. La desigualdad de la inflación modifica la renta y riqueza de la gente. Puede haber cambiado el número de habitantes (independientemente de la expansión monetaria) y la composición de los distintos sectores de la población. Tal vez se hayan registrado progresos técnicos y cabe que haya cambiado la demanda de los bienes. La situación final a la que tiende el mercado ya no es la misma situación a la que tendía antes de las perturbaciones provocadas por la expansión monetaria. 


\section{Pensamiento Crítico Vol. $17 \mathrm{~N}^{\circ} 2$}

\section{Conclusiones}

Por lo tanto, hay inversiones hechas durante el auge que no pueden ser aprovechadas, porque el precio de los productos no compensa el dinero que la explotación de tales instalaciones exige invertir; tal dinero se necesita, con mayor urgencia, para satisfacer otras necesidades, según demuestra el hecho de que tal dinero será más rentable en otras actividades. Pero, habrá torpes inversiones cuyas perspectivas no sean tan pesimistas. De haberse hecho un cálculo económico objetivo, el dinero no se hubiera invertido en esas torpes inversiones. Los factores de producción inconvertibles empleados se consideran dilapidados. Por su propia condición de inconvertibles, son cómplices, que plantea nueva cuestión. Si los ingresos de la venta de los productos superan los costos operativos, es provechoso continuar la producción. Aun cuando (dados los precios que los consumidores están dispuestos a pagar ) la totalidad de las inversiones no resulte rentable; una parte (por pequeña que sea) de esas inversiones si es rentable. La proporción improductiva se considera pérdida sin contrapartida: capital malbaratado y perdido.

Esas realidades, examinadas desde el punto de vista de los consumidores; sugieren las mismas conclusiones. Las necesidades de los consumidores se verían mejor atendidas; si los espejismos provocados por el dinero barato no hubieran inducido a los empresarios a malgastar los escasos bienes de capital, desviándolos de actividades en los que hubieran permitido satisfacer necesidades más urgentemente sentidas por los consumidores, para dedicarlos, en cambio, a la atención de otras necesidades menos urgentes. Por el momento, los consumidores renuncian a satisfacciones que podían haber disfrutado de no haber provocado la expansión monetaria torpes inversiones. Los consumidores pueden, al menos, consolarse parcialmente, pensando disfrutar de bienes que (de no haberse perturbado la actividad económica por el despilfarro del auge) les hubieran sido prohibitivos. Débil es tal compensación, pues esos otros bienes, de los que no pueden disponer por la torpeza con que han sido invertido los factores de producción, les interesan mucho más que esos sustitutos que ahora se les ofrecen.

La expansión monetaria empobrece a la gente. Habrá quienes aprovechan la coyuntura para enriquecerse (personas cuyo razonamiento no ha perturbado la histeria general y que han sabido aprovechar las oportunidades que les brindaba la movilidad del inversionista). Otras personas, sin mérito personal, también saldrán favorecidas 


\section{Pablo Rivas Santos}

porque los bienes vendidos por ellas se iban encareciendo antes que las personas que compraban. Sin embargo, la mayoría pagará en carne propia el exagerado consumo y la torpeza inversionista del episodio inflacionista.

Que la gente, después de la inflación, sea más pobre que antes de la inflación depende de circunstancias particulares de cada caso. Al decir que la expansión monetaria empobrece, se destaca que la gente, al sufrir la expansión monetaria, se empobrece en comparación a las satisfacciones que habría disfrutado de no haberse producido esa expansión monetaria. La historia registra un progreso económico ininterrumpido, un continuo incremento de bienes de capital, un alza permanente del nivel de vida. Ese progreso se produce a un ritmo tan rápido que logra compensar y superar las pérdidas provocadas por el excesivo consumo y las torpes inversiones de la expansión monetaria. En tales casos, el sistema económico goza, después del auge, de mayor prosperidad que antes de producirse el auge; sin embargo, la gente se considera empobrecida al darse cuenta las aún enormes posibilidades de mayor prosperidad que han sido debilitadas y desperdiciadas.

\section{Referencias bibliográficas}

Barro, Robert (1990). Macroeconomía. Madrid: Alianza Editorial. Segunda edición.

Friedman, Milton (1985). Moneda y desarrollo. Buenos Aires: Editorial Ateneo.

Friedman, Milton (1976). Teoría de Precios. Segunda edición.

Kemmerer, Edwin Walter. El ABC de la inflación. BCRP.

Ropcke, Wilhelm (1967). Economía Política. Madrid: Alianza Editorial.

Rothbard, Murray (1980). Moneda libre y controlada. Buenos Aires: Centro de estudios sobre la libertad.

Von Hayek, Friedrich (1960). Precios y Producción. McGraw-Hill.

Von Mises Ludwig (1981). Acción Humana. Valencia: Fundación Ignacio Villalonga. 